\title{
Specially Protected Natural Areas as a Means of Forming the Ecological Culture of learners
}

\author{
Aleksandr Semenov, Valentina Ilyina* , Anna Mitroshenkova and Ekaterina Makarova \\ Samara State University of Social Sciences and Education, 443090, Antonov-Ovseenko Str., 26, \\ Samara, Russia
}

\begin{abstract}
Natural and territorial complexes, including specially protected objects, are important in the formation of ecological culture of the younger generation. Samara oblast (European part of Russia) has a unique system of specially protected natural territories with various characteristics of vegetation, fauna, landscapes. This provides acquaintance of learners with various ecosystems in the territory available for visiting. In order to increase the effectiveness of the process of forming environmental culture it is recommended to use a practice-oriented approach in environmental education: organization and carrying out environmental actions, expeditions, excursions, environmental trails, as well as research, project, labor, environmental protection and volunteer activities. We have developed an algorithm for conducting educational and research activities for schoolchildren and research activities for students to study the current state of specially protected natural areas.
\end{abstract}

\section{Introduction}

Ecological education plays an integrative role in the system of continuous education. It contributes to formation and development of a holistic worldview of learners; forms their system thinking, civic consciousness and skills of forecasting consequences of human activity impact on nature; gives humanistic orientation to education; promotes moral, patriotic, civic, ethic and aesthetic upbringing of young generation. The foundation of environmental education is made by natural science knowledge, which forms a balanced, competent understanding of the surrounding world, reasonable attitude to the phenomena and processes occurring in it [3-8].

The purpose of environmental education is to form an environmental culture of the individual. The most effective environmental culture is formed with a practice-oriented approach to the educational process, when learners are involved in various activities (research, project, labor, environmental protection, volunteering), organized in the framework of academic and extracurricular activities.

The most important source of knowledge and means of forming environmental culture is nature, its unique natural and territorial complexes, including specially protected natural areas.

* Corresponding author: $\underline{5 \text { iva } @ \text { mail.ru }}$ 
The purpose of this work is to determine the educational potential of specially protected natural territories in the formation of environmental culture of learners.

\section{Materials and Methods}

The methodological, theoretical and methodological basis for the research in the field of environmental education are the works of S.V. Alekseev, N.D. Andreeva, S.N. Glazachev, A.N. Zakhlebny, N.V. Meh, T.M. Nosova, I.N. Ponomareva, N.Z. Smirnova, V.P. Solomin. To achieve the goal, we used traditional methods of pedagogical research, such as the study of scientific and methodological literature on the problem of forming environmental culture of learners, the method of theoretical analysis and synthesis.

The concept "ecological culture" is considered in the works of researchers from different positions. Some of them define ecological culture as a special type of culture which has arisen in the period of population growth and intensive scientific and technical revolution. Others consider the ecological culture as a specific type of ethics, as a system of morality. Still others understand ecological culture as a part of the universal culture, built on national experience and traditions.

D.S. Likhachev defined ecological culture as ecology of culture itself, as education of live love to the native land, as formation of moral culture of the person [4].

According to I.N. Ponomareva and V.P. Solomin, "ecological culture is a system of value-oriented ecological knowledge, activity and relations" [7].

Y.M. Popov and N.N. Sazonova consider that "ecological culture should be considered as a system concept, the most important and integral component of human culture. It includes a system of mental, moral and ethical, patriotic, legal, aesthetic values of man and society, contributing to the conservation of natural resources, environmental security, sustainable socio-economic and cultural development of all mankind and each of its individual representatives" [8].

Many researchers agree that the leading role in the development of personal environmental culture belongs to the system of environmental education. The system of ecological education possesses those tools (educational technologies, methods, means, forms of training and education) which will influence on formation of ecological thinking, ecological consciousness and outlook, ecological beliefs and ecologically justified behavior. At formation of ecological culture of learners, the essential role plays the personality of the teacher, his competence and moral qualities. Undoubtedly, specially protected natural areas have significant potential for the development of environmentally educated and cultural society $[3,6,10]$.

\section{Results and Discussion}

General results of environmental education are expressed in the categories of knowledge, skills, attitudes, activity experience and competencies combined in some criteria, such as ecological erudition, the nature of the subjective attitude to nature and healthy lifestyles, the ability to reasonable thought activity based on the ecological imperative. As a result, a personality is formed, included in the world of nature. In the system of environmental education there are various effective forms that contribute to the formation of environmental culture of learners. Among them are environmental camps, gatherings and actions, expeditions, excursions, environmental trails.

The listed organizational forms are practice-oriented and refer to practical ecology, which is based on a combination of various types of activity: reproductive, searchcognitive, search-creative levels. Occupation with the practical issues related to ecology is a 
kind of life school for the future generation, which will have to act in accordance with the principles of sustainable development of society. Therefore, practical ecology is considered as a universal form of role practice for learners, having as a prerequisite socially significant result of activity.

For a variety of reasons, the environmental education of the younger generation is often based only on their mastery of the theoretical foundations of ecology and nature conservation. Often learners are deprived of communication with nature. Unfortunately, this is also the case when unique natural complexes, including specially protected natural areas of various statuses, are located in the immediate vicinity of organizations conducting educational activities.

However, despite the emerging difficulties, in Samara oblast there is a team of likeminded teachers (biologists, geographers, historians), teachers of additional education and university teachers, who fully use the educational potential of specially protected natural areas to form an environmental culture of learners through their involvement in research, project, labor, environmental activities, as well as environmental volunteerism.

It should be noted that there is a rich complex of ecological-phytocenotic conditions and diverse vegetation (pine forests, broad-leaved forests, steppes, meadows, coastal and aquatic vegetation) on the territory of some natural sites. This can provide learners with an introduction to different ecosystems characteristic of the region, on a relatively small territory.

Transition years for Russia 1991-2000 had a noticeable impact on the state of natural complexes of the Samara oblast [1,2]. Thus, 6 of 9 natural monuments in Krasnoyarsk district were destroyed: "Bolshekamenskaya" and "Bolshekamenskaya light" dry oak forests were cut down, "Bolshekamenskaya", "Malorakovskaya" and "Malokamenskaya" forest-steppes were plowed, the former quarry "Vodinskie Minerals" was given for dacha construction. Natural and territorial complexes "Gatnoye Lake", "Alekseevskie Lakes", "Sukhoi Pond", "Voronezh Ponds" and many others lost their status of local nature monuments. Recreational and economic use of these territories led to the loss of natural features, ecosystem role, scientific and educational potential.

On the territory of Samara oblast there are specially protected natural areas of federal significance: Zhigulevsky State Natural Biosphere Reserve named after I.I. Sprygin, National Parks "Samarskaya Luka" and "Buzuluksky Bor", as well as 214 natural monuments of regional importance. Recreational activities, including school ecological tourism and other activities in the field of education and upbringing of young people are currently carried out in many areas.

We have developed interesting excursion routes and environmental trails in areas with different natural characteristics: Kamenny Dol, Chubovsky steppe, Studeny ravine, Koptev ravine, Yaitsky lakes, Samara floodplain and others.

In the modern period, due to the development of GIS-technologies, studies of SPNAs are becoming very accurate and allow the locations of specific species of fauna, flora and plant communities to be marked immediately in nature on topographic maps.

In the practice of teaching and research activities it is possible to use the general methodological techniques of studying individual components of SPNAs (for example, physical-geographical, botanical, zoological, edaphic, ecological, recreational, sociological and etc.).

The implementation plan includes five main stages: organizational, methodological, experimental, analytical and implementation of the results.

Characteristics of some of the main stages. Stage 1: Organizational. Includes the conclusion of agreements to perform research work with learners, partnership agreement, obtaining medical certificates of health. 
Stage 2: Methodological. To distribute tasks on the study of individual components of SPNAs among all team members in advance and prepare for them. Conducting the environmental part of the study is impossible without knowledge of the legal framework, geographical location, area, a list of the main objects of protection, the regime of special protection of SPNAs, so all the work of the team needs careful planning. During the research of the selected SPNAs it is necessary to take photographs, which will be useful for further analysis of information and to illustrate the conclusions.

Physico-geographical studies:

- information about physico-geographical parameters of SPNAs of Samara oblast can be obtained on the Official website of the Ministry of Forestry, Environment Protection and Nature Management of Samara oblast in the "Cadastre of specially protected natural areas of regional importance" posted there and by analyzing the corresponding satellite images of the area. Task: Using Google-maps service, find the SPNAs you are studying. Make a screenshot and add it to your report.

- study such characteristics of SPNAs as macro- and micro-relief of the area, condition of the surface soil layer, surface bedrock, moisture conditions, sodding, human and animal impact.

Botanical research:

- study the species composition, age and quantitative characteristics of the flora of SPNAs;

- identify rare and protected species of SPNAs flora;

- analyze the flora of SPNAs according to taxonomic, ecological, ecobiomorphological, ecological-phytocenotic and resource criteria;

- to study the plant communities of SPNAs;

- assess the condition of the vegetation cover of SPNAs according to geobotanical criteria (what is the species composition of the phytocenosis, tiering, the abundance of species composition, the occurrence of individual species, density, phenological state, aspect of the phytocenosis). Zoological research:

- To study the species composition of the available fauna of SPNAs. It should be remembered that the study of the species composition of invertebrates and vertebrates requires special techniques.

Environmental studies:

- evaluate the extent to which of SPNAs is subject to anthropogenic impact (presence of trash, trampling, fire marks and etc.);

- assess the stability of the flora of SPNAs in terms of species composition and how it corresponds to the indigenous phytocenoses of the area (the presence of weeds and adventive plants in the flora and etc.);

- evaluate the species composition of phytocenoses of SPNAs based on the presence and distribution of populations of rare and protected plant species;

- assess the species composition of the flora of SPNAs to determine the resources of useful plants;

- assess the species composition of phytocenoses to identify relict and endemic elements in the flora of the studied of SPNAs;

- evaluate the condition of the soil cover of SPNAs for recommendations on the ecological evaluation of lands and determination of the productivity of steppe and grasslands;

- identify which animals inhabit of SPNAs and assess their status (common or rare, not inhabited, occurring very rarely, occurring quite often);

- to estimate the level of stability of the wildlife component of SPNAs biocenosis (not stable, stable); 
- to draw conclusions about the structure of SPNAs biocenosis and its surroundings (multi-component and stable, low-component and unstable);

- assess the degree of ecological condition of SPNAs (relatively satisfactory, tense, critical, crisis, catastrophic);

- make a forecast of possible changes in the structure of the biocenosis of SPNAs.

Stage 4: Analytical. It includes the analysis of empirical data obtained; analysis of information from printed and electronic sources; preparation of the text of the work for peer review.

In mastering them, learners are able to develop a system of activities that allow them to gather information and analyze the factual material obtained. The priority is always reconnaissance expedition trips to different administrative districts of the oblast with the establishment of stationary observation sites of SPNAs, where the degree of impact of human activity on different biogeocenoses and their individual components is assessed. In these areas there are also long-term observations of the state of flora and vegetation cover. Classic examples of the use of specially protected natural areas as potential sites for research activities of students are "Sernovodskiy shihan", "Verkhovye Binaradka River", "Maytugan Depression", "Igonev Dol" and others.

Learners who have mastered the methods of studying of SPNAs have the competencies to assess and predict the dynamic trends of natural-territorial complexes in conditions of anthropogenic transformation of the natural environment. They are also able to develop and implement strategies and tactics of rational nature management.

\section{Conclusions}

Due to the high diversity of species and cenotic composition, specially protected natural areas of Samara oblast have a high educational potential for the formation of ecological culture of learners. This process is facilitated by practice-oriented forms of learning.

Modern Russian environmental legislation allows organizing specially protected natural areas with the status of natural monuments of local (municipal, district) importance [9]. Unfortunately, by the present time there are no such natural monuments in the Samara oblast. This causes anxiety and concern of ecologists and citizens not indifferent to the problems of ecology. The promotion of conservation ideas at the local level is promoted by enthusiastic and caring teachers with their students (pupils or students) by conducting research on the current state of natural complexes, identifying rare and protected species on their territory, justifying the need to protect them and giving them the status of municipal nature monuments, as well as environmental volunteerism aimed at environmental protection activities. Such a practice-oriented approach contributes not only to the acquisition of new knowledge, skills, activity experience and competencies by learners, but also to a more effective formation of their value orientations towards nature and environmental culture.

It should be noted that the involvement of learners in research activities of environmental orientation, equips them with specific knowledge, encourages creative work on environmental education and increases the level of professional pedagogical training of future teachers.

This research project a state assignment of the Samara State University of Social Sciences and Education.

\section{References}

1. V. N. Ilyina, A. E. Mitroshenkova, Problems of Modern Biology, XII, 20-21 (2014) 
2. V. N. Ilyina, A. E. Mitroshenkova, A. A. Ustinova, Samara Scientific Bulletin, 3(4), 41-44 (2013)

3. G. E. Kudinova, S. V. Saxonov, S. A. Senator, Problems of enterprise development: theory and practice. Materials of the 15th International Scientific-Practical Conference dedicated to the 85th anniversary of Samara State University of Economics: in 2 parts, 297 (Samara, 2016)

4. D. S. Likhachev, The Past to the Future (Nauka, Leningrad, 1985)

5. T. M. Nosova, L. A. Kolyvanova, and V. G. Shvedov, Scientific Reflection, 5-6(910), 121-123 (2017)

6. R. Mathevet, J. D. Thompson, C. Folke and others, Ecological Applications, 26 (1), 24701216 (2016)

7. I. N. Ponomareva, V. P. Solomin, Ecological Education in the Russian School: History. Theory. Methodology (Publishing house of Russian State Pedagogical University named after A.I. Gertsen, St. Petersburg, 2005)

8. Y. M. Popov, N. N. Sazonova, Samara Scientific Bulletin, 6, 4(21), 243-246 (2017)

9. S. A. Rogov, Ecological and geographical problems of Russian regions: materials of $X$ All-Russian scientific-practical conference with international participation, dedicated to the 100th anniversary of the birth of Prof. V.I. Prokayev and 90th anniversary of the natural-geographical faculty of SSPU, 251-254 (SGSPU, Samara, 2019)

10. S. A. Senator, I. V. Kazantsev, T. B. Matveeva, G. E. Kudinova, Azimuth of Scientific Research: Pedagogy and Psychology, 6, 3(20), 228-233 (2017) 